Doctors in training should have protected time to attend high quality, relevant education and this should be audited. Before 2018, Regional Level 3 Paediatric teaching was delivered on a mainly ad hoc basis, with deficiencies reported in addressing curriculum competencies by recent GMC and NES (NHS Education for Scotland) surveys.

Aim To assess the success of a new regional Level 3 teaching programme in providing accessible, relevant teaching to trainees.

Methods A new committee of senior trainee volunteers, with a Consultant Supervisor, was set up. Themes from the $\mathrm{RCPCH}$ Progress Curriculum were identified, to be delivered monthly on a rolling annual basis. Focus groups of committee members organised and led each session. Attendance was taken, and attendance certificates were awarded after feedback form submission. After one year of implementation, trainees completed an online survey assessing their opinion of the new teaching programme. Members of the teaching committee filled in an additional survey relating to their role.

Results The average number of trainees attending per session was 19. Overall, attendance was 51\% ST6, 29\% ST7 and $20 \%$ ST8. Percentage of trainees present per session from total trainees at site (over 6 sites) ranged from 23\% to $62 \%$ (Median 45\%). 83\% provided feedback. Each session score was above 4 (on a scale of 1-5) with a range of 4.06 to 4.92. $95 \%$ of trainees found the sessions accessible, and $76 \%$ enjoyed the face-to-face nature. $90 \%$ agreed or strongly agreed that the teaching was relevant to their stage of training.

$56 \%$ of committee members were ST8, 33\% ST7, and $11 \%$ ST6. $100 \%$ reported that they had a clear idea of session focus and $86 \%$ that it was easy to record attendance and feedback. Committee members felt well supported in $100 \%$ of cases. Formal feedback was provided to speakers in $100 \%$ of cases.

Conclusions The programme is well received by trainees, who find sessions accessible and useful. Volunteers find organising straightforward and well supported. Attendance, however, varies by site and grade. Our next steps are to evaluate future NES and GMC surveys, and facilitate improved attendance.

\section{G209(P) WHAT IMPACTS PAEDIATRIC TRAINEES' PERCEPTIONS OF BLOGS?}

GF Appleby. University Hospital Lewisham, London, UK

\subsection{6/archdischild-2020-rcpch. 177}

Aims To explore what affects paediatric trainees' views about blogs as learning tools.

Methods Trainees volunteered to complete an online survey and/or participate in a 1:1 interview, all responses were pseudo-anonymised. A modified constructive grounded theory approach was used to analyse the results.

Results Twenty-three trainees participated, table 1:

Blog experiences can be categorized as being determined by: self, others and organisational factors.

Self: Trainees' blog use was found to be on a spectrum ranging between: non-user, casual user, active follower and sharer. No participants identified as blog creators, which could be an additional subgroup. Trainees who reported being non-

\begin{tabular}{lllll}
\multicolumn{4}{l}{ Abstract $\mathbf{G 2 0 9 ( P )}$ Table $\mathbf{1}$} & \\
\hline $\begin{array}{l}\text { Trainee } \\
\text { Grade }\end{array}$ & Survey & Interview & Both & Total \\
\hline ST1-3 & 8 & 1 & & \\
ST4-5 & 5 & 2 & 1 & 8 \\
ST6-8 & 4 & 1 & 1 & 6 \\
Total & 17 & 4 & 2 & 23 \\
\hline
\end{tabular}

users were sceptical about the accuracy of the writing on blogs as the information may be unchecked especially if unreferenced.' ST1-3. Whereas, for others the gains from readership outweighed doubts, although tension between trusting blogs fully was pervasive throughout all interviews. Benefits relating to clinical practice included: improved communication skills, affirming practice and knowledge acquisition. Other advantages included: perspective and connectivity.

Others' Influence: Blog access was influenced by direct recommendations, which were mostly made by registrars and/or consultants. These nudges also occurred from institutions: 'by having the stamp of approval [Organisation] [this] was something ... of an endorsement' Blake. A blog writer's reputation could also influence trainees in deciding whether to engage; for example, when a blog is written 'by a Dr whom I know is one of the leading people... I feel quite safe....that it's pretty reputable' Taylor.

Organisational Factors: This can relate to stylistic features such as ease of access which was the most important influence on user experience. Equally support at an organisational level also 'gives it that little bit of extra sway... [for trainees] to start engaging with it' Blake.

Conclusions This project illustrates there are a myriad of interlinking factors that influence trainees' perceptions and experience of blogs. An understanding of this complexity may aid future development and design of blogs and online educational content.

\section{Association of paediatric emergency medicine}

\section{G210 ADDRESSING PAEDIATRIC OBESITY IN THE EMERGENCY DEPARTMENT: CLINICIANS CURRENT ATTITUDES AND THE BARRIERS THEY FACE - A PERUKI STUDY}

${ }^{1,2} \mathrm{R}$ Tricks, ${ }^{2} \mathrm{C}$ Gough, ${ }^{3} \mathrm{E}$ Walton. ${ }^{1}$ Faculty of Medicine and Health, University of Leeds, Leeds, UK; ${ }^{2}$ Emergency Department, Nottingham University Hospitals, Nottingham, UKi ${ }^{3}$ PERUKI, UK

\subsection{6/archdischild-2020-rcpch.178}

Background Rates of childhood obesity are increasing. Traditional strategies including school nurses are overwhelmed. Strategies to discuss weight and impact on health, including 'Make every contact count', are challenging in the Emergency Department (ED), in part due to rising attendances and an increasingly strained service. Other 'Quick-win' interventions (e.g. smoking cessation) have been attempted in ED. Ascertaining the current attitudes of clinicians towards addressing obesity in the ED and the barriers they face can support development of long term solutions to obesity management in children. 
Aims Explore whether clinicians working in EDs address paediatric obesity, identify obstacles, and seek opinions on whether this can be improved.

Methods A survey was distributed to clinical staff seeing children in EDs through the PERUKI network. Data were analysed to identify current attitudes towards addressing obesity, obstacles, and ideas for improvement.

Results 693 responses were received from 57 sites. Current rates of addressing obesity are low. 127 (18.3\%) respondents address it with nearly every/every patient. Paediatric/ Paediatric Emergency Medicine (PEM) doctors are more likely than Non-paediatric/PEM doctors or Advanced Care/ Emergency Nurse Practitioners. (AC/ENP) (25.6\% v 12.3\%, $\left.\chi^{2}=20.26, \mathrm{p}<0.0001\right)$. Barriers included: lack of referral options $(78.6 \%)$, time $(77.8 \%)$, concern regarding negative responses (77.3\%), obesity being a familial issue (61\%) and lack of training (53.1\%). 'Concern regarding negative responses' was the most commonly cited barrier for those from Non-Paediatric/PEM doctors (83.2\%) and AC/ENP's (84.1\%). 'Lack of training' was higher amongst Non-Paediatric/PEM doctors (63.9\%) and AC/ENP's (71\%). 'Concern regarding negative responses' was also highest in those working $0-5$ yrs in ED (81.6\%), whereas 'Lack of time' was the biggest barrier in those working over 10 years in ED. To improve addressing obesity within EDs clinicians requested support with diagnosis, easier referral pathways, training, and changes in ethos both within departments and at local and national levels.

Conclusions Like other healthcare professionals, ED clinicians currently face many barriers in addressing obesity with their patients. However, by addressing these at a local and national level, the majority of ED clinicians feel they can have a role in helping to address the paediatric obesity crisis.

\section{G211 DESIGNING A CRITICAL CARE OUTREACH SERVICE - AN AUDIT AND NATIONAL SURVEY}

N Peshimam, S Stockinger, J Weber, R Mitting. Paediatric Intensive Care Unit, Imperial College Healthcare NHS Trust, London, UK

\subsection{6/archdischild-2020-rcpch.179}

Critical Care outreach services for adults have been shown to reduce mortality. It has also been demonstrated consistently that review of step-down patients on the ward reduces readmission to ICU and is therefore cost effective. There is, however, no published evidence on the benefit or lack thereof of critical care outreach services for children.

The Bedside PEWS score has been found to predict critical deterioration with a median score of 8 in deteriorating patients on paediatric wards.

A review of recent serious incident investigations within our NHS Trust identified a common theme of 'failure to escalate care in the deteriorating patient.'

Aims With a view to designing a critical care outreach programme, we completed a national survey of all British paediatric intensive care units to discover what percentage of units have a funded service, and whether this is staffed by nurses or doctors. We then carried out a review of the last 1 year of 'internal collapse' admissions from the paediatric wards to PICU within 1 NHS Trust to assess the time of day that critical care admissions most commonly occurred, and to confirm that a BPEWS of 8 would predict deterioration in our population.

Method A telephone survey of all PICUs listed in the PICANET database. A case note review of the previous 1 year of admissions to PICU from wards within the same hospital. Recorded was time of admission, BPEWS score at admission, and maximum BPEWS in the 12 hours prior to admission.

Results Of the 27 PICUs listed in the database, 9 have funding for a critical care outreach service. In all apart from 1 this was a nurse led service.

The mean and median PEWS scores for the internal collapse patients were 8 at the time of admission, and a mean maximum of 9 during the previous 12 hours.

$39 \%$ of admissions to PICU from paediatric wards occurred between 0800-1700 hrs, 45\% between 1400-2200 hrs and 26\% between 2200-0800 hrs.

Conclusion A third of PICUs had a dedicated critical care outreach service. A day-time only service would miss $25 \%$ of admissions. A BPEWS of less than 8 should be used as a trigger for review.

\section{G212 FEASIBLITY AND ACCEPTABILITY PILOT OF A PUBLIC HEALTH INTERVENTION DELIVERED IN THE PAEDIATRIC EMERGENCY DEPARTMENT}

${ }^{1,2}{ }^{R E}$ Isba, ${ }^{1}$ RL Edge. 'Lancaster Medical School, Lancaster University, Lancaster, UK; ${ }^{2}$ Emergency Department, North Manchester General Hospital, Manchester, UK

10.1136/archdischild-2020-rcpch.180

Aim Paediatric Emergency Departments (PEDs) are well-placed to deliver public health interventions. Whilst numerous studies describe the effectiveness of a range of ED-based interventions for adults, less has been done to assess interventions for Children and Young People (CYP).

Every year in England, millions of CYP attend hospital, often with relatively minor illnesses/injuries, which sometimes result in long waits - time that could be used to improve wider health and wellbeing.

This pilot study assessed the feasibility and acceptability of delivering a public health intervention in the PED of a busy district general hospital.

Methods Full prospective ethical approval was obtained. Participants were CYP and their carers attending a PED in England. An opportunistic sampling strategy was used, with a focus on recruiting those who had a wait whilst in the department.

The intervention was a consultation delivered by a public health specialist, based around the 'Screening, Brief Intervention, and Referral for Treatment' (SBIRT) model and focussed on: household smoking, vaccination status, dental health, and frequent attendance.

Quantitative outcome data (e.g. registering with dentist) were collected by phone at one week and then one, three, and six months post-enrolment (where indicated). Qualitative data came from engaging with participants and completion of a field diary by the public health specialist (primary researcher).

Results Thirty participants were recruited over the two-week pilot, with $50 \%$ of CYP participating in the consent process. Twenty participants (67\%) triggered at least one screening question, with dental health and (household) smoking being the most common triggers. 